vivors were interviewed about the advice they had been given during and after their admission concerning smoking, diet, and exercise. When appropriate, patients were asked whether the result of serum cholesterol estimation had been discussed with them. Results were analysed with the $\chi^{2}$ test with Yates's correction.

There were 142 eligible admissions ( 85 men). Thirty patients died before interview, and 17 refused consent or had dementia. The 95 subjects ( 58 men) interviewed had a median age of 75 (range $70-86$ ) and were interviewed a median of 8.6 (range 2.6-14) months after admission. Fifteen had regularly smoked cigarettes. Twelve had been advised to stop and 11 had either done so or cut down considerably. One of the three with whom smoking had not been discussed had also stopped.

Fifteen patients had previously been given dietary advice for medical reasons. Of these, six had been advised to make further changes and four claimed to have done so. Of the 80 patients not previously on a diet, 36 remembered having been given advice: nine from a doctor and 21 from a nurse or dietitian, while six had been given a booklet. Two thirds of these claimed to have made positive changes to their diet (specific changes were recalled by 12 of the 24 ) compared with eight of the 44 not given advice $\left(\chi^{2}=6 \cdot 0, \mathrm{df}=1, \mathrm{p}=0 \cdot 009\right)$.

The serum cholesterol concentration was available in 63 cases: the median was 6.4 (range $3 \cdot 8-10 \cdot 0) \mathrm{mmol} / \mathrm{l}$, and 12 subjects had a concentration $\geqslant 7.8 \mathrm{mmol} / \mathrm{l}$. Nine patients could recall having discussed their cholesterol concentration with a member of staff.

Fifty one people recalled a discussion about exercise. All but five of these said that they had followed the advice. More detailed analysis was not possible because the advice given varied depending on individual circumstances.

For logistical reasons we did not attempt to verify smoking habits or change in diet, and this should be taken into account when interpreting our results. Nevertheless, we confirmed that fit older people are prepared to heed advice on lifestyle and make beneficial changes after admission to a coronary care unit for a suspected myocardial infarction.

D L COHEN

S FOWLIE

Department of Clinical Gerontology,

Radcliffe Infirmary,

Oxford

1 Beard K, Bulpitt C, Mascie-Taylor H, O'Malley K, Sever P, Webb S. Management of elderly patients with sustained hypertension. BMJ 1992;304:412-6. (15 February.)

\section{Notifiable diseases}

SIR,-Though I welcome Bryan Jefferson Heap's reminder of the statutory obligation on all medical practitioners to notify certain diseases, ${ }^{1}$ is it not time that infectious diseases epidemiologists reexamined the methods used to ascertain cases of infection of importance to public health? Presently formal notification, laboratory returns, information from reference laboratories or "spotter" general practitioners, absences from employment, hospital discharges and deaths, and death certificates are all used by many workers but in an uncoordinated fashion with little linking of cases to obtain the true incidence or, more importantly, to initiate action in terms of public health.

The methods used should match the disease. In 1991, 37539 cases of chickenpox were statutorily notified in Scotland. ${ }^{2}$ This is a disease presently subject only to surveillance. The $£ 75000$ spent on reimbursing practitioners would have been more appropriately used in establishing a representative sample of sentinel doctors to obtain the true incidence of this and other conditions.

It has been proposed that listeriosis should be made a notifiable disease. ${ }^{3}$ From 1967 to 1991,155 cases not associated with pregnancy were ascertained in Scotland. One hundred and twenty four were reported by laboratories, 84 were listed in the reference laboratory records, and 67 were listed in the national hospital discharge and death files (unpublished information). Thus reporting based on clinicians would have identified only half the cases identified by laboratories.

A Hill shows the importance of notification with respect to surveillance of measles. ${ }^{+}$This disease has clear diagnostic criteria and is almost invariably diagnosed clinically, and public health intervention is possible - namely, a two stage immunisation programme with mumps, measles, and rubella vaccine for boys and girls.

The challenge facing consultants in public health medicine (communicable diseases and environmental health) and communicable disease control is to develop surveillance methods appropriate to specific diseases and their potential for action in terms of public health.

D M CAMPBELI

Environmental Health (Scotland) Unit,

Ruchill Hospital,

Glasgow G20 9NB

1 Heap BJ. Notifiable diseases. BMF 1992;304:726-7. (21 March.) Weekly Report 1992;26:7.

3 Social Services Committee. First report. Food poisoning: listeric and listeriosis: follow up. London: HMSO, 1989:iv.

Hill A. Measles, mumps, and rubella vaccination. BMF 1992 304:779. (21 March.)

SIR,-Simon Voss has shown ignorance among doctors of the procedure for notifying infectious diseases, ' and the accompanying editorial outlines other problems such as poor compliance and an outdated list of notifiable diseases. ${ }^{2}$ The shortfalls of the notification system do not end there. The system is also inaccurate, relying on clinical diagnosis rather than laboratory confirmation; slow (notifications in Winchester Health District are often received after, and as a result of, laboratory diagnosis); and entails expensive administration of a derisory payment.

The aims of notification are twofold: to permit rapid intervention to prevent an outbreak, and surveillance. Neither is achieved by the present system, but both are done much more efficiently by microbiology laboratorles. In many microbiology laboratories the isolation of important pathogens requiring rapid intervention is reported quickly to those responsible for controlling infection, usually the hospital infection control doctor and more recently the consultant in communicable disease control. Laboratory reporting of microbial isolates to the Communicable Disease Surveillance Centre is thorough, accurate, and sufficiently rapid for surveillance purposes even though there is no statutory obligation. It is true that laboratories can report only on the specimens they receive, but this gives a far more accurate picture of the true incidence of infectious disease than a poorly compliant notification of clinical suspicion.

Is notification ever worth while? It may still have a role in community acquired infections that are less commonly confirmed by a laboratory, such as viral exanthemas and pertussis, and infection in which laboratory diagnosis is often delayed, such as tuberculosis. The table compares the numbers of statutory notifications received and of microbiology reports to the Communicable Disease Surveillance Centre for several conditions. Enteric infections are grossly undernotified. Notifications and microbiology reports for turberculosis are identical. In contrast, viral exanthemas are more commonly notified than reported by microbiological laboratories.

The current process of statutory notification is anachronistic. Though notification of some infections may still be useful, the process needs to be reviewed. This has been initiated by the Department of Health, although no recommendations
Numbers of statutory notifications of selected infectious diseases and microbiology reports to Communicable Disease Surveillance Centre in Winchester Health District, August 1991 to March 1992

\begin{tabular}{lrr}
\hline & Notifications & $\begin{array}{c}\text { Microbiology } \\
\text { reports }\end{array}$ \\
\hline $\begin{array}{l}\text { Enteric infection (food } \\
\text { poisoning) }\end{array}$ & 128 & 398 \\
$\begin{array}{l}\text { Tuberculosis } \\
\text { Meningitis }\end{array}$ & 5 & 5 \\
Measles & 4 & 11 \\
Mumps & 74 & \\
Rubella & 4 & 2 \\
\hline
\end{tabular}

have yei been announced. ${ }^{3} \mathrm{~A}$ rapid response to potential outbreaks of infection is ensured if the consultant in communicable disease control maintains close liaison with the microbiology laboratory as well as general practitioners and environmental health officers. Surveillance of most infectious disease is most effectively achieved through microbiology laboratory reports to the Communicable Disease Surveillance Centre.

MATTHEW DRYDEN RICHARD GABB

Department of Microbiology,

Royal Hampshire County Hospital

Winchester SO22 5DG

1 Voss S. How much do doctors know about the notification of infectious diseases. BMF 1992;304:755. (21 March.)

2 Jefferson Heap B. Notifiable diseases. BMJ 1992;304:726-7. (21 March.)

3 Department of Health. Review of law on infectious disease control-consultation document. London: $\mathrm{DoH}, 1989$.

\section{Maternity services}

SIR,-Though I well understand the need for liberalisation of maternity services in the United Kingdom, I believe that the report of the Commons select committee goes too far.

For the past nine years in this district we have had the benefit of excellent maternity services from Hinchingbrooke Hospital. Here women enjoy the best of all worlds. They are encouraged to choose and plan their own arrangements for labour and delivery, which is led by a midwife. Surroundings are pleasantly informal, and facilities are available to aid active birth. On the other hand, the full technological facilities of a modern unit are available should the need arise. The result of this is an extremely low rate of instrumental deliveries and the lowest perinatal mortality rate in the country. Therefore few women in the district see anything to be gained from a home delivery. During these nine years only three women from our practice (having five births between them) have opted for a home delivery.

I have elected to try to attend these deliveries to support the midwife, but it is ridiculous to pretend that I now have sufficient skills in intrapartum care to be of anything other than decorative value. At the same time these events are extremely time consuming, and if they occurred more frequently they would be completely incompatible with the post-1990 schedule of general practice. Our last home delivery entailed a midwife being in attendance almost continuously for 16 hours and a doctor for six hours - a service that would have been impossible to provide had the delivery not occurred on a Saturday when neither of us was on call.

The select committee is therefore being completely unrealistic in its expectation that all general practices can offer a home delivery service. This would require a massive increase in the numbers of both midwives and skilled general practitionerobstetricians. Instead maternity services should continue to be concentrated in hospitals (including rural isolated general practitioner units, where the necessary skills in intrapartum care remain) So far as the role of midwives and the need for 